\title{
Performance Test of Rice Seed and Fertilizer metering Mechanism
}

\author{
Cui Hongguang \\ College of Engineering \\ Shenyang Agricultural University \\ Shenyang, China \\ Cuihongguang7763@163.com
}

\author{
Ren Wentao * \\ College of Engineering \\ Shenyang Agricultural University \\ Shenyang, China \\ Rwtsyau@sina.cn \\ * Corresponding Author
}

\begin{abstract}
The quadratic regression general rotating combination experiment with four factors on the vertical double-disc pneumatic seed and fertilizer-metering mechanism was carried out to assure the rate and spacing of the seed and fertilizer on the paper tape during the operation of rice seed tape twisting machine. The regression equations of the seed sucked qualification ratio and the fertilizer sucked qualification ratio with experimental factors were set up respectively. The effect of the factors on evaluating indexes was analyzed and the optimum parameters were determined. The results showed that the main evaluating indexes for the mechanism were seed sucked qualification ratio of $86.32 \%$ and the fertilizer sucked qualification ratio of $87.44 \%$ at the seed-metering shaft speed of $15.31 \mathrm{r} / \mathrm{min}$, seed disc sucking hole diameter of $1.5 \mathrm{~mm}$, fertilizer disc sucking hole diameter of $2.0 \mathrm{~mm}$ and the sucking chamber vacuum of $4.4 \mathrm{kPa}$. The indexes of the mechanism fulfill the basic requirements during the performance test.
\end{abstract}

Keywords- rice direct sowing; rice; seed tape; neumatic seed-metering device; direct sowing technology

\section{INTRODUCTION}

direct sowing has played an important role in rice planting technology for the advantages of lower cost, water saving, less processes, labor saving, higher profits, etc.

The United States, Australia and the other developed countries do rice direct sowing by aircraft(Zhou, 1999). Rice seedling transplanting is the principal growing patern in Japan, Korea and some other Asian countries, Mechanical rice direct seeding developed rapidly in recent years (Bao, 2007).

Different planting systems and different mechanized cultivation modes are formed for the different geographical and climate conditions in each area of China, and the main planting mode is rice seedling transplanting. In recent years, rice direct sowing machine in China developed rapidly because of lack of water resources. With the development of precision agriculture, China put forward several new rice planting technologies and related machinery in recent years. They are mainly the precision rice hill-direct-sowing technology(Luo, 2005, 2007, 2008; Wang, 2010), the pre-germinated rice seed direct sowing technology(Xue, 1999; Li, 2000), the rice mulching direct sowing technology(Ren, 2003), and the rice seed tape direct sowing technology.
The paper carrier rice seed rope direct sowing technology with multi-materials is based on the technology with single seed. It could realize sowing the seed, fertilizer and other materials according to the agricultural requirement in the same time which reduce the times of machinery or labour working in the paddy field.

The rice seed tape direct sowing technology with multi-materials demands the seed and fertilizer fall on the non-woven fabric at a certain speed and seed and fertilizer spacing. The seed and fertilizer metering mechanism need to be manufactured to realize the quantities of seed and fertilizer. The seed and fertilizer guiding mechanism need to be manufactured to realize the positioning of seed and fertilizer. The experimental study on vertical double-disc pneumatic seed and fertilizer metering mechanism of the designed machine was carried out and the effects of the factors on quality of the machanism were analyzed. It may provide a basis for integration and production of the rice seed tape twisting machine.

\section{MATERIALS AND METHODS}

\section{A. Materials}

The rice variety for test is Shendao 7 (cultivated in Shenyang Agricultural University national rice seed multiplication base), which is suitable for direct sowing in Shenyang area. The fertilizer is granular DAP (diameter in the range of $2 \sim 4 \mathrm{~mm}$, which produced in the Qiangdao gangsi zhongnong chemical imports and exports Co., Ltd.)

\section{B. Methods}

The quadratic regression general rotating combination experiment with four factors was carried out in the laboratory of College of Engineering, Shenyang Agricultural University, at the environmental temperature of $16^{\circ} \mathrm{C}-22^{\circ} \mathrm{C}$ and the relative humidity of $35 \%-50 \%$.

The ranges of the factors (the speed of seed-metering shaft, diameter of seed disc sucking hole, diameter of fertilizer disc sucking hole and the vacuum of sucking chamber) were determined according to analysis of the vertical double-disc pneumatic seed-metering and fertilizer-metering mechanism. The Working principle of the mechanism is shown in Fig.1. Fan motor starts to produce a certain pressure on both sides of the disks for seed and fertilizer, seed-metering disk and fertilizermetering disk rotates at same speed driven by step motor. 
When the seed-metering disk works in the process in the order of sucking seed, clearing seed, bringing seed and throwing seed, the fertilizer-metering disk works in the same order with fertilizer on the disk. Seed and fertilizer leaves each disk at their outlets under gravity and go respectivly to the guiding device and at last fall on the nonwoven fabric at a certain speed and spacing of seed and fertilizer. Coding of factors and levels of the experiment is listed in Table 1.

\section{Selection and determination of performance indexes}

The main evaluating indexes for the mechanism are the seed sucked qualification ratio $\left(\mathrm{Y}_{1}\right)$ and the fertilizer sucked qualification ratio $\left(\mathrm{Y}_{2}\right)$ during experiment. The others are seed leaked ratio, multiple seed ratio, fertilizer leaked ratio and multiple fertilizer ratio.

The qualification ratios of the seeds and fertilizer are measured with a SONY DSC-H10 camera of the frame rate of $25 \mathrm{fps}$; then it was edited and calculated with a video editing software.

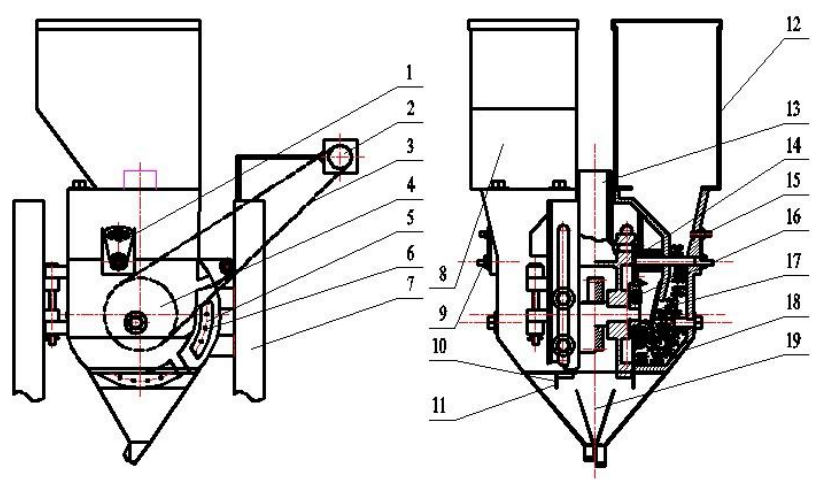

1. Adjustment device for fertilizer clearing 2. Stepper motor 3. Chain 4 Driving shaft 5. Fertilizer-metering disk 6. Fertilizer sucked hole 7 Support frame 8 . seed box 9. Adjustment device for seed clearing 10 . Seed-metering disk 11. Seed sucked hole 12. fertilizer box 13. Air pipeline 14. Clearing brush for more fertilizer 15. Adjustment nut for clearer 16. Block for fixing disks 17. Control panel 18. Box 19. Guiding device for seeds and fertilizer

Figure 1. Figure 1. Principle of the vertical double-disc pneumatic seed-metering and fertilizer-metering device

TABLE I. CODING FOR FACTORS AND LEVELS OF THE EXPERIMENT

\begin{tabular}{ccccc}
\hline & \multicolumn{4}{c}{ Factors } \\
\cline { 2 - 5 }$x_{j}$ & $\begin{array}{c}Z_{1} \\
\text { the speed } \\
\text { of shaft } \\
/\left(\mathrm{r} \mathrm{min}^{-1}\right)\end{array}$ & $\begin{array}{c}Z_{2} \\
\text { diameter of } \\
\text { seed disc } \\
\text { sucking hole } \\
/ \mathrm{mm}\end{array}$ & $\begin{array}{c}Z_{3} \\
\text { diameter of } \\
\text { fertilizer disc } \\
\text { sucking hole } \\
/ \mathrm{mm}\end{array}$ & $\begin{array}{c}Z_{4} \\
\text { vacuum of } \\
\text { sucking } \\
\text { chamber } \\
/ \mathrm{kPa}\end{array}$ \\
\hline+2 & 20 & 2.5 & 3 & 7.0 \\
+1 & 16.5 & 2.3 & 2.6 & 5.75 \\
0 & 13 & 2 & 2.3 & 4.5 \\
-1 & 9.5 & 1.7 & 1.9 & 3.25 \\
-2 & 6 & 1.5 & 1.5 & 2.0 \\
\hline
\end{tabular}

\section{RESULTS AND DISCUSSION}

The quadratic regression general rotating combination experiment plan with four factors is shown in Table 2. The experiments were carried out as the plan and the the seed sucked qualification ratio and the fertilizer sucked qualification ratio were recorded.

\section{A. Establishment of the regression equation}

Based on Origin Software, the regression equation with the objective function of the seed sucked qualification ratio is obtained with statistical methods of the quadratic regression general rotating combination test and eliminate not significant terms at level $\mathrm{p}=0.05$ as:

$$
\begin{aligned}
& Y=80.164-2.803 x_{1}-10.512 x_{2}-5.276 x_{4} \\
& -3.891 x_{2} x_{4}-2.538 x_{1}^{2}-3.061 x_{2}^{2}-2.963 x_{4}^{2}
\end{aligned}
$$

The regression equation with the objective function of the fertilizer sucked qualification ratio is obtained with statistical methods of the quadratic regression general rotating combination test and eliminate not significant terms at level $p=0.05$ as:

$$
\begin{aligned}
& Y=79.260-3.371 x_{1}-8.026 x_{3}-4.480 x_{4} \\
& +2.641 x_{1} x_{4}-5.098 x_{3} x_{4}-3.317 x_{1}^{2}-3.981 x_{3}^{2}-2.634 x_{4}^{2}
\end{aligned}
$$

The significance test to the regression equation for lack of fit was done by calculating the sum of deviation squares and degrees of freedom. For fitting equation of the seed sucked qualification ratio, $\mathrm{F}_{1}=1.858<\mathrm{F}_{0.05}(10,6)=4.06$, and $F_{2}=8.599>F_{0.01}(14,16)=3.45$; for fitting equation of the fertilizer sucked qualification ratio, $\mathrm{F}_{1}=2.41<\mathrm{F}_{0.05}(10,6)=4.06$, and $\mathrm{F}_{2}=7.007>\mathrm{F}_{0.01}(14,16)=3.45$. It showed that the lack of fit tests was not significant and the regression equations were significant. So the quadratic model can represent the relationship between the selected factors and the seed sucked qualification ratio and the fertilizer sucked qualification ratio respectively.

TABLE II

TESTING PROGRAM AND RESULTS

\begin{tabular}{ccccccc}
\hline $\begin{array}{c}\text { Test } \\
\text { number }\end{array}$ & x1 & x2 & x3 & x4 & $\begin{array}{c}\text { seed sucked } \\
\text { qualificatio } \\
\text { n ratio /\% }\end{array}$ & $\begin{array}{c}\text { the fertilizer } \\
\text { sucked } \\
\text { qualification } \\
\text { ratio /\% }\end{array}$ \\
\hline 1 & 1 & 1 & 1 & 1 & 53.18 & 52.88 \\
2 & 1 & 1 & 1 & -1 & 67.12 & 65.91 \\
3 & 1 & 1 & -1 & 1 & 54.24 & 79.70 \\
4 & 1 & 1 & -1 & -1 & 66.52 & 76.82 \\
5 & 1 & -1 & 1 & 1 & 83.18 & 58.48 \\
6 & 1 & -1 & 1 & -1 & 85.30 & 67.73 \\
7 & 1 & -1 & -1 & 1 & 82.12 & 81.52 \\
8 & 1 & -1 & -1 & -1 & 85.00 & 75.91 \\
9 & -1 & 1 & 1 & 1 & 48.95 & 45.79 \\
10 & -1 & 1 & 1 & -1 & 73.42 & 70.53 \\
11 & -1 & 1 & -1 & 1 & 47.11 & 83.16 \\
12 & -1 & 1 & -1 & -1 & 76.05 & 82.37 \\
13 & -1 & -1 & 1 & 1 & 81.05 & 48.95 \\
14 & -1 & -1 & 1 & -1 & 87.11 & 77.63 \\
15 & -1 & -1 & -1 & 1 & 79.21 & 83.42 \\
16 & -1 & -1 & -1 & -1 & 85.53 & 86.84 \\
17 & -2 & 0 & 0 & 0 & 86.25 & 80.83 \\
18 & 2 & 0 & 0 & 0 & 53.50 & 50.25 \\
19 & 0 & -2 & 0 & 0 & 85.38 & 82.88 \\
20 & 0 & 2 & 0 & 0 & 50.19 & 87.12 \\
21 & 0 & 0 & -2 & 0 & 83.65 & 70.58 \\
22 & 0 & 0 & 2 & 0 & 80.58 & 55.19 \\
23 & 0 & 0 & 0 & -2 & 75.58 & 77.69 \\
24 & 0 & 0 & 0 & 2 & 60.77 & 58.85 \\
25 & 0 & 0 & 0 & 0 & 84.23 & 74.81 \\
26 & 0 & 0 & 0 & 0 & 79.23 & 82.50 \\
27 & 0 & 0 & 0 & 0 & 81.73 & 74.62 \\
28 & 0 & 0 & 0 & 0 & 77.50 & 81.35 \\
29 & 0 & 0 & 0 & 0 & 87.50 & 86.35 \\
30 & 0 & 0 & 0 & 0 & 72.31 & 75.00 \\
31 & 0 & 0 & 0 & 0 & 78.65 & 80.19 \\
\hline & & & & & &
\end{tabular}




\section{B. Testing of the regression coefficients}

The F-test to the significance of regression coefficients was conducted. The results showed that for the seed sucked qualification ratio, the coefficients $x_{2}, x_{4}, x_{2}^{2}, x_{4}^{2}$, $x_{2} x_{4}$ are highly significant, $x_{1}$ and $x_{1}^{2}$ are significant, coefficients of other terms are not significant at level $\mathrm{p}=0.05$; for the fertilizer sucked qualification ratio, the coefficient $x_{1} 、 x_{3} 、 x_{4} 、 x_{1}^{2} 、 x_{3}^{2} 、 x_{4}^{2} 、 x_{3} x_{4}$ are highly significant, $x_{1} x_{4}$ are significant, and coefficient of other terms are not significant at level $\mathrm{p}=0.05$.

\section{Main effect analysis}

The factors in the experimental design are treated and coded dimensionlessly and linearly, and the partial regression coefficients have been standardized. So the absolute value of the first-order coefficients can be a direct reflection of the impact of each variable to indexes. From (1) and (2), it can be seen that for the seed sucked qualification ratio, the significance order of the effects is that diameter of seed disc sucking hole>the vacuum of sucking chamber> the speed of seed-metering shaft> diameter of fertilizer disc sucking hole; for the fertilizer sucked qualification ratio, the significance order of the effects is that diameter of fertilizer disc sucking hole $>$ the vacuum of sucking chamber> the speed of seed-metering shaft> diameter of seed disc sucking hole, and they are all negative effects to the indexes.

\section{Effect analysis of single factor}

Effect of single factor on the seed sucked qualification ratio and the fertilizer sucked qualification ratio with other factors kept to level zero are shown respectively in Fig.2. The seed sucked qualification ratio is not sensitive to diameter of fertilizer disc sucking hole of a horizontal line, the other three factors are all in the para-curve with the opening downward, which shows that the effect of the three factors on the seed sucked qualification ratio increased firstl and then decreased (Fig.2(a)). The fertilizer sucked qualification ratio is not sensitive to diameter of seed disc sucking hole of a horizontal line, the other three factors are all in the para-curve with the opening downward, which shows that the effect of the three factors on the fertilizer sucked qualification ratio increased first and then decreased (Fig.2 (b)).

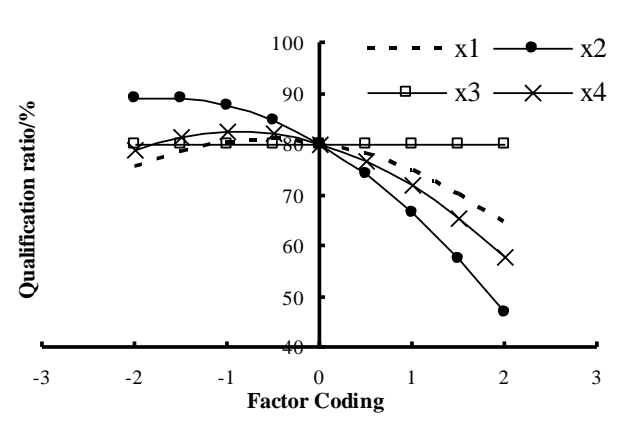

(a) Seed sucked qualification ratio

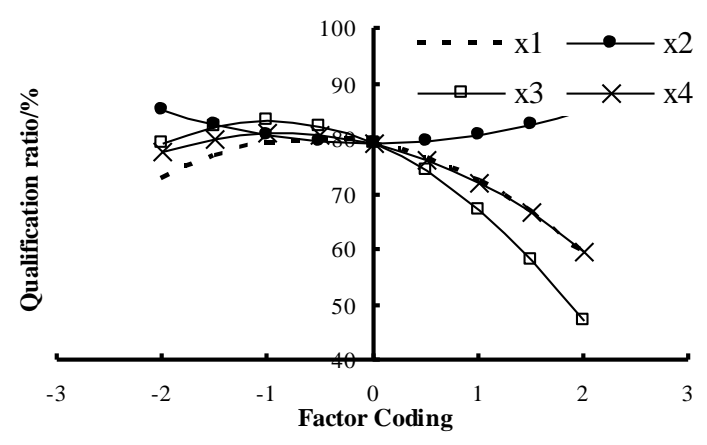

(b) Fertilizer sucked qualification ratio

Notes: $x_{1}$-shaft speed/( $\left(\mathrm{min}^{-1}\right) ; x_{2}$-rice disk suction hole diameter $/ \mathrm{mm} ; x_{3}$-fertilizer disk suction hole diameter $/ \mathrm{mm} ; x_{4}$-chamber pressure $/ \mathrm{kPa}$.

Figure 2. Efect of Single factors

\section{E. Effect analysis of interaction}

In the quadratic regression model of the seed sucked qualification ratio established, the interactive coefficient $x_{2} x_{4}$ in the regression equation is significant at level $\mathrm{p}=0.01$. The analysis of the interaction is shown in Fig.3.

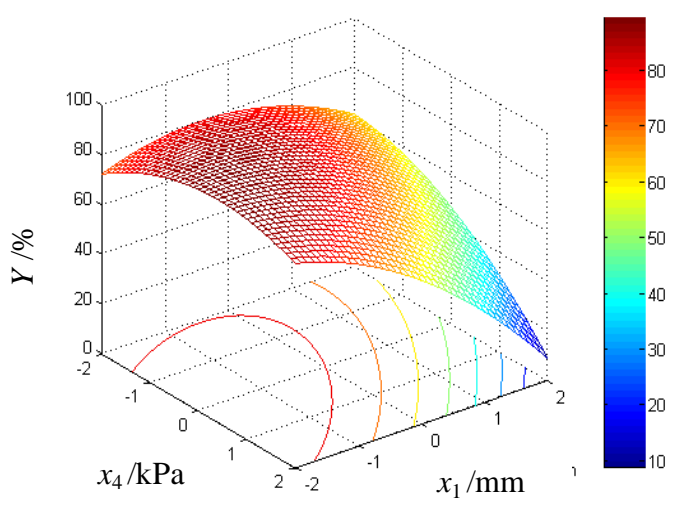

Notes: $x_{2}$-diameter of seed disc sucking nole $/ \mathrm{mm} ; x_{4}$ - vacuum of sucking chamber $/ \mathrm{kPa} ; Y$-the seed sucked qualification ratio/\%。

Figure 3. Influence of the seed sucked ratio in the ac tion of interaction
The seed sucked qualification ratio could reach a maximum range when the diameter of seed disc sucking hole within the range of $-2 \sim 1$ (that is $1.5 \sim 2.3 \mathrm{~mm}$ ) and the vacuum of sucking chamber within the range of $-2 \sim 2$ (that is $2.0 \sim 7.0 \mathrm{kPa}$ ).

In the quadratic regression model of the fertilizer sucked qualification ratio established, the interactive coefficient $x_{1} x_{4}$ in the regression equation is significant at level $\mathrm{p}=0.05, x_{3} x_{4}$ is significant at level $\mathrm{p}=0.01$. So the analyses of the interactions are performed as are shown in Fig.4. The fertilizer sucked qualification ratio could reach a maximum range when the speed of seed-metering shaft within the range of $-2 \sim 1$ (that is $6 \sim 16.5 \mathrm{r} / \mathrm{min}$ ) and the vacuum of sucking chamber within the range of $-2 \sim 1$ (that is 2.0 5.75 $\mathrm{kPa}$ ) (Fig.4(a)). The fertilizer sucked qualification ratio could reach a maximum range when the diameter of fertilizer disc sucking hole whthin the range of $-2 \sim 1$ (that is $1.5 \sim 2.3 \mathrm{~mm}$ ) and the vacuum of sucking chamber within the range of $-2 \sim 2$ (that is $2.0 \sim 7.0 \mathrm{kPa}$ ) (Fig.4(b)). 


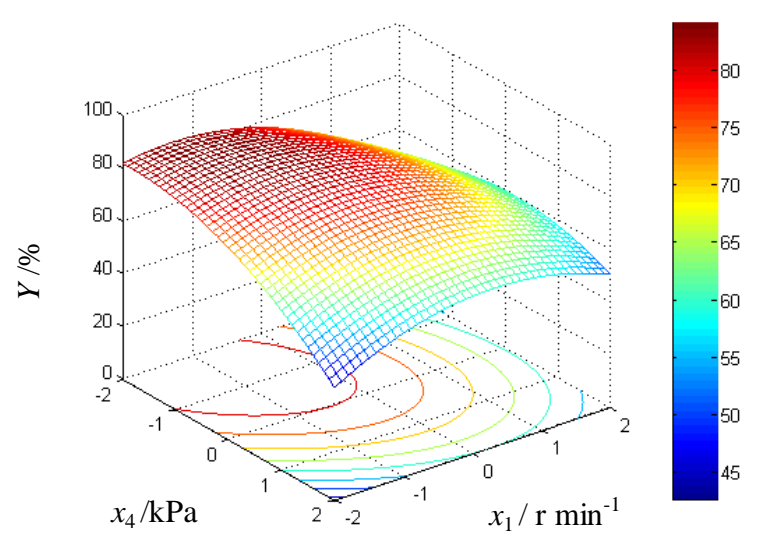

(a) influence of $x_{1}$ and $x_{4}$

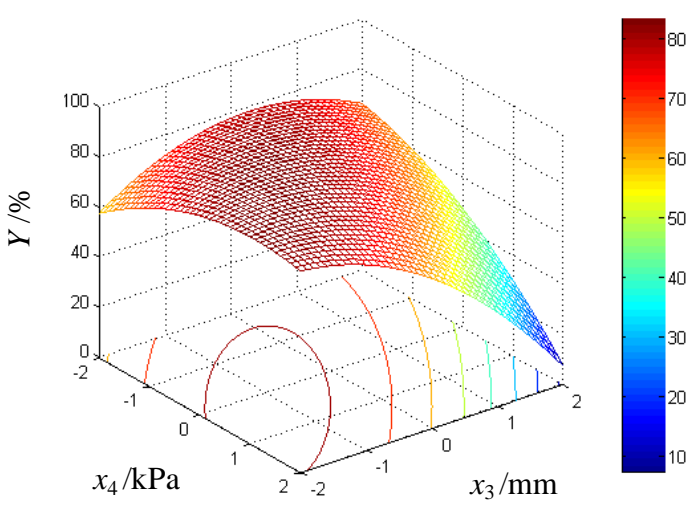

(b) influence of $x_{3}$ and $x_{4}$

Notes: $x_{1}$-the speed of seed-metering shaft $/\left(\mathrm{r} \mathrm{min}^{-1}\right) ; x_{3}$-diameter of fertilizer disc sucking hole $/ \mathrm{mm} ; x_{4}$-the vacuum of sucking chamber $/ \mathrm{kPa} ; \quad Y$-the fertilizer sucked qualification ratio/\%。

Figure 4. Influence of the fertilizer sucked ratio in the action of interactive factors

\section{F. Comprehensive optimization analysis}

According to balance method based on multiple indexes, the seed sucked qualification ratio and fertilizer sucked qualification ratio should be reach the maximum in the constraint conditions respectively. The experiment is a multi-objective decision which should meet $\max Y_{1}$ and $\max Y_{2}$.

The constraint conditions of the test level code $x_{i}$ are:

$$
\left\{\begin{array}{c}
Y_{j} \geqslant 0 \\
-2 \leqslant x_{i} \leqslant 2
\end{array} \quad(j=1,2 ; i=1,2,3,4)\right.
$$

The optimum parameters combination is $x_{1}=0.66, x_{2}=-2$, $x_{3}=-0.93$, and $x_{4}=-0.08$, based on the weight coefficient of 5:5 between the seed sucked qualification ratio and the fertilizer sucked qualification ratio according to the analyzing of metering performance. According to the transformation formula of the experimental factor and the coding, the predicted seed sucked qualification ratio is $88.79 \%$ and seed sucked qualification ratio may be $91.68 \%$ while the seed-metering shaft speed of $15.31 \mathrm{r} / \mathrm{min}$, the seed disc sucking hole diameter of $1.5 \mathrm{~mm}$, the fertilizer disc sucking hole diameter of $2.0 \mathrm{~mm}$ and the sucking chamber vacuum of $4.4 \mathrm{kPa}$. Experiment was carried out to verify the optimized results. The results showed that the seed sucked qualification ratio is $86.32 \%$ and fertilizer sucked qualification ratio is $87.44 \%$. These values are similar to the theoretical predictions, so the optimization is reliable.

\section{G. Image observation}

The process and analysis of the experiment are based on image acquisition; the typical images are shown in Fig.5 and Fig.6. Fig.5 are the images of seeds in sucked status as follows: single seed sucked on the tangent line (a), single seed sucked with one end in the hole (b), single seed sucked on radial direction (c), multiple seeds sucked on one hole (d), no seed sucked on hole (e). Fig.6 are the images of fertilizer in sucked status as follows: single fertilizer sucked on hole (a), no fertilizer sucked on hole (b), multiple fertilizer sucked on one hole (c).

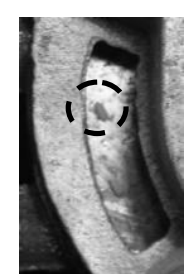

(a)

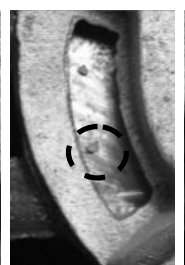

(b)

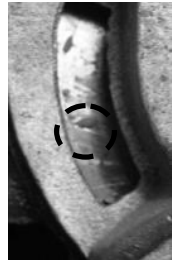

(c)

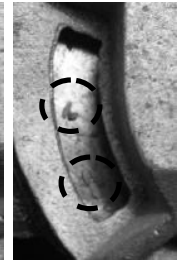

(d)

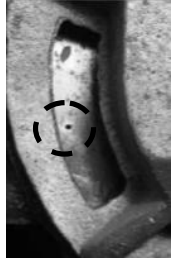

(e)
Figure 5. The postures of sucked rice seeds

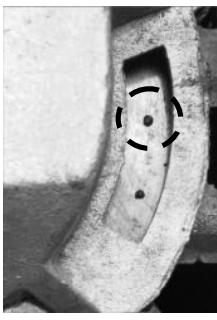

(a)

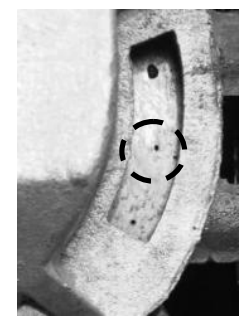

(b)

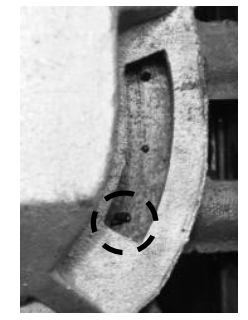

(c)
Figure 6. The postures of sucked fertilizers

\section{CONCLUSIONS}

(1) The regression equations of the seed sucked qualification ratio and the fertilizer sucked qualification ratio are established respectively with quadratic polynomial regression model.

(2) The significance order of the effects for the seed sucked qualification ratio is that the diameter of seed disc sucking hole $>$ the vacuum of sucking chamber $>$ the speed of seed-metering shaft $>$ diameter of fertilizer disc sucking hole. The significance order of the effects for the fertilizer sucked qualification ratio is that diameter of fertilizer disc sucking hole $>$ the vacuum of sucking chamber $>$ the speed of seed-metering shaft> diameter of seed disc sucking hole.

(3) The optimum parameters were determined through the quadratic regression general rotating combination test of four factors. The seed sucked qualification ratio of $86.32 \%$ and the fertilizer sucked qualification ratio of $87.44 \%$ at the seed-metering shaft speed of $15.31 \mathrm{r} / \mathrm{min}$, 
seed disc sucking hole diameter of $1.5 \mathrm{~mm}$, fertilizer disc sucking hole diameter of $2.0 \mathrm{~mm}$ and the sucking chamber vacuum of $4.4 \mathrm{kPa}$. It assured the accuracy number of seed and fertilizer to the guiding device to meet the requirements of the rice seed tape twisting mechanism.

\section{ACKNOWLEDGMENT}

The authors acknowledge the financial support from Natural Science Foundation of China (50775150), The National High Technology Research and Development Program of China (863 Program) (2012AA10A501, SS2012AA100901).

\section{REFERENCES}

[1] Zhou Y. H., and Z. H. Yuan. "Mechanization of rice production in the United States". Chinese Agricultural Mechanization, 1999, (6),pp. 41-42.

[2] Bao, C. J., and R. L. Wang. Overview on mechanization technology of rice direct sowing in Japan. Agricultural Science \& Technology and Equipment, 2007, (6) ,pp. 23-25.

[3] Yuan, Z. H. Study on the breakthrough and across in the mechanization of rice cultivation in China. Chinese Agricultural Mechanization, 2002, (2) ,pp. 46-48.

[4] Luo, X. W., E. C. Jiang, and Z. M. Wang. Precision rice hill-drop drilling machine. Transactions of the CSAE, 2008, 24(12) ,pp. 5256.

[5] Luo, X. W., and T. Liu. Design and experiment of hill sowing wheel of precision rice direct-seeder. Transactions of the CSAE, 2007, 23(3) ,pp. 108-112.

[6] Luo, X. W., Z. Ou, and E. C. Jiang. Experimental research on precision rice direct-seeder with hill sowing. Transactions of the Chinese Society for Agricultural Machinery, 2005, 36(9) ,pp. 3740.

[7] Luo, X. W., W. P. Xie, and Y. G. Ou. Experimental investigation of different transplanting methods in paddy production. Transactions of the CSAE, 2004, 20(1),pp. 136-139.

[8] Wang Z. M., and X. W. Luo. Precision rice hill-direct-seeding technology and machine based on the combination of agricultural machinery and agronomic technology. Journal of South Chine Agricultural University, 2010, 31(1),pp. 91-95.

[9] Xue, Y. Y. Promotion of rice bud seedling throwing technology to perfect modern agronomic techniques. Shanghai Agricultural Science and Technology, 1999, (2),pp. 26-27.

[10] Li, Z. Y. Direct sowing technology over $700 \mathrm{~kg}$ per mu. Shanghai Agricultural Science and Technology, 2000, (1) ,pp. 20.

[11] Ren, W. T., and M. J. Xin. Effects of paper-mulching rice planting technology on water saving and weed control. Transactions of the CSAE, 2003,19(6) ,pp. 60-63.

[12] Lv, X. R., and W. T. Ren. Analysis and research for the technology of rice direct sowing with seed rope. Journal of Agricultural Mechanization Research, 2008, (1),pp.212-215.

[13] Ren, W. T., X. S. Li, and H. G. Cui. Effect of the technigue of rice direct sowing with seeds twisted in paper rope on rice yield character. Journal of Shenyang Agricultural University, 2005, 36(3) ,pp. 265-270.

[14] Ren, W. T., X. S. Li, and Y. S. Zhang. Development and experiment on a rice seed rope twisting machine. Journal of Agricultural Mechanization Research, 2005, (6) ,pp. 169-172.

[15] Zhou, J., and C. Y. Ji. Development of machine for producing precision seeding rope with paper for rice direct sowing. Transaction of the CSAE, 2009. 25(7) ,pp. 79-83.

[16] Zhou, J., and C. Y. Ji. Machine for producing rice seed rope and field experiment. Journal of China Agricultural University, 2009,14(2) ,pp. 98-102.

[17] He, R. Y., H. Y. Luo, and Y. T. Li. Comparison and analysis of different rice planting methods in China. Transactions of the CSAE, 2008, 24(1) ,pp. 167-171.

[18] Cui, H. G. and W. T Ren. Performance test of rice seed tape twisting mechanism. International Agricultural Engineering Journal, 2012, 21(3-4) ,pp.59-64.

[19] Qiao, X. J., Z. R. Shen, and Q. Y. Chen. Design and realization of general computer monitoring and controlling system for environment of agricultural facilities. Transactions of the CSAE, 2000. 16(3) ,pp. 77-80.

[20] Yang, S. F., J. M. Zhao, and X. Q. Wang. Food texture detection system based on virtual instrument technology. Transactions of the CSAE, 2007. 23(8) ,pp. 176-180. 